\title{
Growth of Bulk Gallium Nitride Single Crystal by Sodium Flux Method: A Brief Review
}

\author{
Nurul Fatihah Nik Sin, Kamarulazizi Ibrahim and Norzaini Zainal* \\ Institute of Nano-Optoelectronics Research and Technology (INOR), \\ Universiti Sains Malaysia, 11800 USM Pulau Pinang, Malaysia \\ *Corresponding author: norzaini@usm.my
}

Published online: 25 August 2019

To cite this article: Nik Sin, N. F., Ibrahim, K. \& Zainal, N. (2019). Growth of bulk gallium nitride single crystal by sodium flux method: A brief review. J. Phys. Sci., 30(2), 189-208, https://doi.org/10.21315/jps2019.30.2.11

To link to this article: https://doi.org/10.21315/jps2019.30.2.11

\begin{abstract}
Growing interest in homoepitaxial growth of nitride-based devices has driven considerable efforts towards producing bulk gallium nitride single crystal as a substrate for the devices. Therefore, the process of producing the bulk gallium nitride crystal substrate should be simple and yet cost-effective to reduce the production cost of the devices. To date, several methods of growing bulk gallium nitride crystal have been proposed. Sodium flux method is one of the most promising ways since it requires a moderate growth temperature and growth pressure, as well as being simple and costeffective. This paper will briefly review the progress made to advance the growth of bulk gallium nitride single crystal by sodium flux method, including discussing challenges and proposing possible improvements in future.
\end{abstract}

Keywords: Bulk GaN single crystal, sodium flux method, spontaneous nucleation, liquid phase epitaxy, LPE

\section{INTRODUCTION}

III-V nitride semiconductor materials, i.e., gallium nitride $(\mathrm{GaN})$ and its alloys have been regarded as the most preferable candidate for novel electronic and optoelectronic devices, particularly light emitting diodes (LEDs). This is because the materials have wide and direct bandgap as compared to other materials like silicon, III-V arsenide and III-V phosphide. Moreover, III-V nitride materials allow the devices based on them to operate at high temperature and high power. The current available GaN-based LEDs are heteroepitaxially grown on sapphire substrate. However, the efficiency of the LEDs remains below $100 \%$. ${ }^{1,2}$ The main 
reason to this issue is related to the large mismatch of lattice structure between sapphire and GaN materials, that results in high threading dislocations. ${ }^{3}$ If such dislocations propagate into multi-quantum wells (MQWs) active region of the LEDs, they would act as non-radiative recombination centres. The centres will significantly reduce the number of electrons and holes to recombine radiatively, thereby impairing the efficiency of the LEDs ${ }^{4}$ For this reason, a strong impetus is now taking place to homoepitaxially grow the LEDs on GaN substrate, of which the presence of the threading dislocations is expected to be almost negligible in the LEDs structure. $^{5}$

So far, several methods have been proposed to grow bulk GaN single crystal. For examples, hydride vapour phase epitaxy (HVPE), high-pressure solution growth (HPSG) and ammonothermal growth. HVPE is the most common method since this method can grow the bulk GaN single crystal at high growth rate of above $100 \mu \mathrm{m} \mathrm{h}^{-1} .{ }^{6}$ In principle, the HVPE growth entails reaction between $\mathrm{GaCl}$ and $\mathrm{NH}_{3}$ to form the $\mathrm{GaN}$ crystal. Prior to the reaction, the $\mathrm{GaCl}$ was formed through reaction between metallic $\mathrm{GaN}$ and $\mathrm{HCl}$. Further details on HVPE growth can be found elsewhere across literature. ${ }^{7}$ Although the system can grow bulk GaN in shorter period of time, it is difficult to maintain stable growth conditions in the HVPE reactor in a long run. In fact, without a proper control of the growth conditions, the GaN crystal tends to crack even at the initial stage of growth. ${ }^{8}$ This may explain why most of the HVPE-grown GaN crystals are suffering from wafer bow/bending. This problem is even more complicated for larger wafer size. ${ }^{9}$ On top of that, the threading dislocations density inside the HVPE grown $\mathrm{GaN}$ crystals is relatively high around $10^{4}-10^{6} \mathrm{~cm}^{-2} .{ }^{10}$

In contrast to HVPE, HPSG and ammonothermal growth are solution-based methods, which are always giving low defects density to bulk GaN single crystal. Boćkowski et al. demonstrated a bulk GaN single crystal growth under high pressure and high temperature. The crystal showed a low dislocation density of $\sim 10^{5} \mathrm{~cm}^{-2} .{ }^{11}$ Nevertheless, the thickness and the area of the crystal are small. This puts the bulk $\mathrm{GaN}$ at disadvantage to become a perfect substrate for developing $\mathrm{GaN}$ based LEDs in larger area. On the other hand, interest in ammonothermal growth has been rising since a decade ago because most of the GaN crystals grown by this method have low threading dislocations density of $\sim 10^{3}-10^{4} \mathrm{~cm}^{-2} .{ }^{12}$ Furthermore, the bending or cracking of the crystal are unlikely through this method. Despite of that, ammonothermal growth is a slower process with the growth rate of about $0.4-17 \mu \mathrm{m} \mathrm{h}^{-1} .{ }^{13}$ In principle, ammonothermal growth is performed in an autoclave and the GaN crystal will be grown from polycrystalline GaN grains or HVPE seeds in a supercritical ammonia solution, in which the temperature and pressure of the ammonia is higher than the critical values. The critical temperature, $T_{c}$ of 
ammonia is $132^{\circ} \mathrm{C}$, while the critical pressure, $P_{c}$ of ammonia is $1636 \mathrm{kPa}$. Since its operation demands for high pressure and high temperature, therefore safety issue is very difficult to handle. A basic explanation of ammonia growth can be found in literature. ${ }^{14}$

Sodium (Na)-flux method is predicted to be among the most promising ways to grow bulk GaN single crystal as compared to the methods as described previously. This method can grow a bulk GaN single crystal at a relatively high growth rate of $\sim 20-50 \mu \mathrm{m} \mathrm{h}^{-1}$ with low threading dislocations of $10^{2}-10^{3} \mathrm{~cm}^{-2} \cdot{ }^{15,16}$ No cracking issue is observable through this method. A group from Tohoku University is amongst the pioneer groups working on this field of area. ${ }^{17}$ In HVPE, HPSG and ammonothermal growth, the quality of the grown bulk GaN single crystal is typically depending on the quality of the seed material. However, this is not the case for Na-flux method through necking technique, whereby high quality bulk GaN single crystals are possible although the seed is poor. ${ }^{18}$ After all, the growth of bulk GaN single crystal by Na-flux method remains under developed but it has a huge prospective to become an alternative method to HVPE in the bulk GaN technology.

This paper will focus on the progress of developing bulk GaN single crystal by Na-flux method. It begins with the principle of growing bulk GaN single crystal through Na-flux method, followed by a review on reported progress of improving the growth of bulk GaN single crystal by manipulating the starting material, introducing additive materials, controlling temperature, pressure and $\mathrm{Ga} /$ $(\mathrm{Na}+\mathrm{Ga})$ ratio, and modifying the growth apparatus. In the end of this report, some improvements in term of increasing the quality of the bulk GaN single crystal as well as its growth time for larger size will be proposed.

\section{BASIC PRINCIPLE OF GROWING BULK GAN CRYSTAL BY NA- FLUX METHOD}

A basic apparatus system for growing a GaN crystal by Na-flux method consists of an autoclave that has a crucible to place $\mathrm{Ga}$ or $\mathrm{Na}-\mathrm{Ga}$ in the melting process, while nitrogen $\left(\mathrm{N}_{2}\right)$ gas flows inside it. From the mechanism of operation standpoint, nitrogen molecules from the gas are ionised by $\mathrm{Na}$ atoms at gas-liquid interface. This causes the ionised nitrogen $\left(\mathrm{N}^{3+}\right)$ to dissolve easily in the Na-Ga melt. ${ }^{19}$ Subsequently, the ionised nitrogen combines with $\mathrm{Ga}$ atoms in the melt to form $\mathrm{GaN}$ material. In this process, the $\mathrm{Na}$ atoms act as a catalyst to enhance the reaction between the nitrogen $(\mathrm{N})$ atoms and the $\mathrm{Ga}$ or $\mathrm{Na}-\mathrm{Ga}$ intermetallic melt. When the $\mathrm{N}$ atoms concentration in the system reaches the maximum value of solubility, a 
spontaneous nucleation of $\mathrm{GaN}$ crystal on a small $\mathrm{GaN}$ crystal seed will take place. This is one of the approaches for growing bulk GaN crystal by Na-flux method.

Another approach is by utilising liquid phase epitaxy (LPE), of which the GaN crystal is growing on a GaN seed. The seed is grown by metal organics chemical vapour deposition (MOCVD) or HVPE. ${ }^{20,21}$ Essentially, it is difficult to grow a large crystal in a diameter directly from the first approach because it demands for longer growth period. On the other hand, the latter approach offers possibility to grow a larger diameter $\mathrm{GaN}$ crystal in more controllable manner than the first approach since the GaN seeds grown by MOCVD and HVPE are readily available in a large diameter up to two inches (2"). By using two-step dislocation reduction, the average bulk GaN sample of 2" diameter surface showed the dislocation density of $\sim 10^{4}-10^{5} \mathrm{~cm}^{-2}$ and the best sample was $\sim 10^{2} \mathrm{~cm}^{-2} .{ }^{15}$ Nonetheless, Mori et al. have made a recommendation that the spontaneous nucleation can potentially produce a better quality thick bulk GaN single crystal in a larger diameter than LPE. ${ }^{22}$ With significant advancements in Na-flux method, the group assured that a 2" diameter $\mathrm{GaN}$ crystal from the seed of spontaneously nucleated GaN crystal can be grown in $\sim 1000 \mathrm{~h}$. The growth of thicker GaN crystal on the seed is also possible by overgrowth with multi times in separate Na-flux growth runs. An example of apparatus to grow a bulk GaN crystal by Na-flux method under temperature gradient can be found in Figure 1 shows the difference of the seed $\mathrm{GaN}$ crystal grown by vapour phase method like MOCVD or HVPE, and spontaneous nucleation. ${ }^{19}$
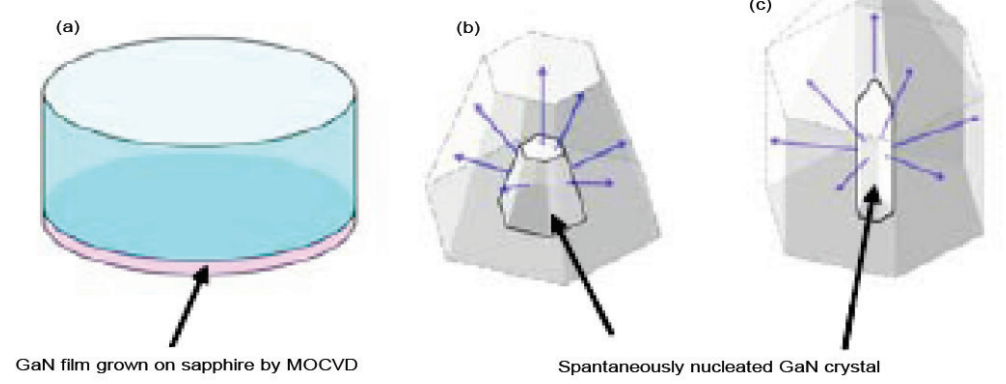

Figure 1: The seed crystal grown by (a) MOCVD or HVPE, and (b and c) spontaneous nucleation. ${ }^{22}$

\subsection{Progress of Growing Bulk GaN Crystals by Na-flux Method}

This section will review works reported towards advancing the growth of bulk GaN crystals by Na-flux method. The reported works have been focused on improving 
the crystal quality of the bulk crystals as well as reducing the growth time for scale-up purpose. Starting materials, additive material, $\mathrm{Ga} /(\mathrm{Na}+\mathrm{Ga})$ ratio or $\mathrm{Ga}$ flux, temperature, pressure and apparatus design are among important factors in advancing the process of growing bulk GaN crystals by Na-flux method. The impact of these factors will be discussed as follows.

The starting materials in Na-flux method are commonly using gallium $(\mathrm{Ga})$ material as the source for $\mathrm{Ga}$, while sodium azide $\left(\mathrm{NaN}_{3}\right)$ for the Na-flux. On the other hand, $\mathrm{N}$ source is supplied from $\mathrm{N}_{2}$ gas. At the initial stage of research in $\mathrm{GaN}$ growth by Na-flux method, Yamane et al. investigated dependence of temperature and $\mathrm{N}_{2}$ pressure on composition of the starting materials of $\mathrm{Ga}$ and $\mathrm{Na}$ at different concentration of $\mathrm{NaN}_{3} \cdot{ }^{17}$ The dependence is shown in Figure 2(a) with the heating time is $24 \mathrm{~h}$.

The molar ratio of $\mathrm{Ga}$ and $\mathrm{Na}$, as given in the figure is calculated using the following equation:

$$
r_{N a}=\frac{N a}{(G a+N a)}
$$

The experiment suggested that the GaN crystals can be grown using Na-flux at the temperature of $600^{\circ} \mathrm{C}-800^{\circ} \mathrm{C}$. Nevertheless, most of the $\mathrm{GaN}$ single crystals are not colourless and non-transparent. The problem can be associated to N-deficiency since the ratio of $\mathrm{Ga} / \mathrm{N}$ was small and close to one. The crystals were grown under low nitrogen pressure. Figure 2(b) shows the scanning electron microscopy (SEM) image of a GaN crystal in a size over $0.1 \mathrm{~mm}$ with of 0.31 .

In the following year, the same group extended the work by manipulating the Ga composition in order to obtain different shape of GaN crystal. ${ }^{23}$ With a fixed temperature of $750^{\circ} \mathrm{C}$ and $\mathrm{NaN}_{3}$ at $3.6 \mathrm{mmol}$, the shape of the $\mathrm{GaN}$ crystal changed from prismatic to platelet and to small grains when the Ga composition was higher. This particular work demonstrated a successful growth of an undoped bulk GaN platelet-crystal basal plane with n-type conductivity in a maximum area of $0.5 \times$ $1.0 \mathrm{~mm}^{2}$ and a high electron concentration of $10^{20} \mathrm{~cm}^{-3}$. The result is comparable to an n-doped GaN-film grown by molecular beam epitaxy (MBE). ${ }^{24}$ From room temperature cathodoluminescence (CL) measurement, the sample showed a strong signal of GaN near-band-edge (NBE) emissions at $363 \mathrm{~nm}$. The crystal is colourless and transparent. 

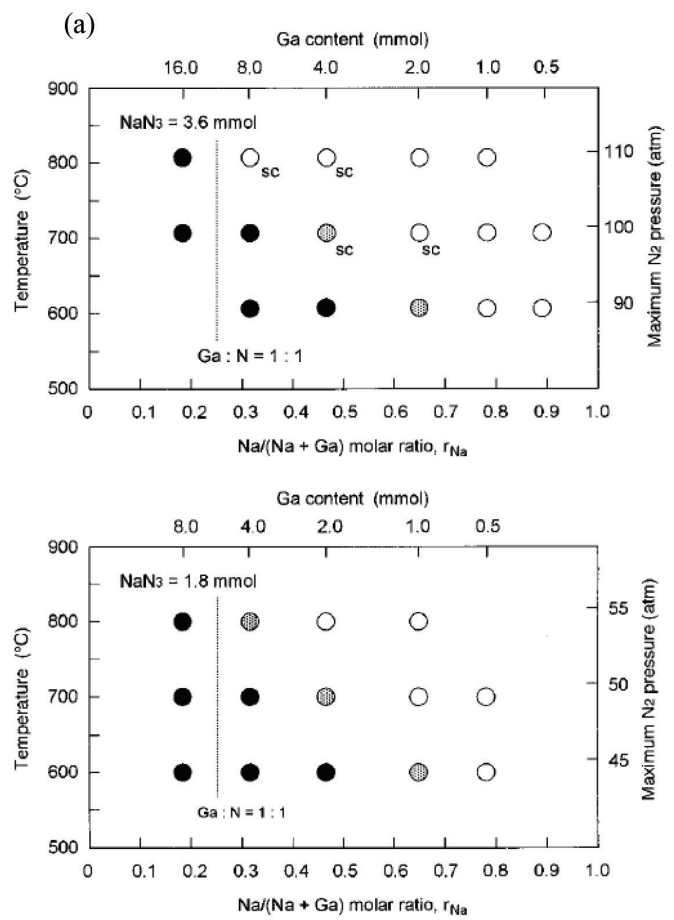

(b)

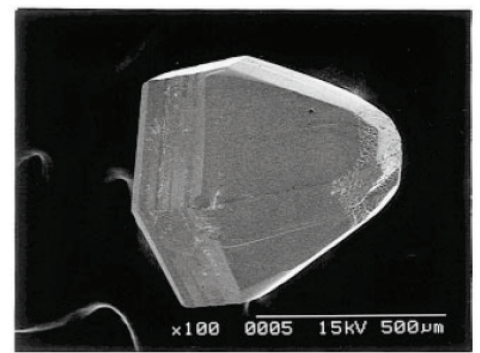

Figure 2: Illustration (a) shows temperature and maximum $\mathrm{N}_{2}$ pressure vs. Ga content and $\mathrm{Na} /(\mathrm{Na}+\mathrm{Ga})$ molar ratio with $\mathrm{NaN}_{3}$ composition of $3.6 \mathrm{mmol}$ and $1.8 \mathrm{mmol}$, respectively. Na-Ga compounds (solid circle), Ga-Na compounds (shaded circle), GaN (open circle) and SC refers to those GaN single crystals produced in a size over $0.1 \mathrm{~mm}$. Illustration (b) shows SEM image of a GaN single crystal formed in the size over $0.1 \mathrm{~mm}$ with of $0.31 .^{17}$

A similar work was reported by Aoki et al. ${ }^{25}$ Instead of controlling the Ga and the $\mathrm{Na}$ compositions, the shape, size and colour of a GaN crystal can be changed by increasing the range of temperature of $750^{\circ} \mathrm{C}-850^{\circ} \mathrm{C}$ and pressure in between 1-5 MPa of $\mathrm{N}_{2}$ for $200 \mathrm{~h}$. They presented a graph that summarises the impact of $\mathrm{N}_{2}$ pressure and temperature on the shape of the GaN single crystal, alongside a lower limit for the $\mathrm{N}_{2}$ pressure to produce the GaN single crystal. The crystal was obtained at lower temperature and/or higher $\mathrm{N}_{2}$ pressure and its shape changed from prismatic to platelet by decreasing temperature and/or increasing the $\mathrm{N}_{2}$ pressure. In contrast, only Na-Ga intermetallic compounds were formed at higher temperature and lower pressure. By slowly increasing the growth temperature, a colourless transparent prismatic single crystal with a dimension of $1.0 \times 0.5 \times$ 
$0.5 \mathrm{~mm}^{3}$ was obtained under $3 \mathrm{MPa}$ of $\mathrm{N}_{2}$. This may imply that the GaN crystal is almost free from the N-deficiency. Despite this, the growth rate is still low.

An attempt to increase the growth rate in the process of Na-flux method was continued by Yamane et al. ${ }^{26}$ They investigated the growth mechanism of the GaN single crystal in a sealed stainless-steel tube container. The temperature was applied at $650^{\circ} \mathrm{C}-840^{\circ} \mathrm{C}$ for $6-300 \mathrm{~h}$. As the Na reactant increased up to $7.2 \mathrm{mmol}$ (with $\mathrm{r}_{N a}=0.52$ ) at $800^{\circ} \mathrm{C}$ for $72 \mathrm{~h}$, platelet $\mathrm{GaN}$ single crystal was grown more on the area up to $15 \mathrm{~mm}$ from the position, where the bottom of the liquid interface was at the beginning of the reaction. The formation of the platelet crystal implied the increase of wettability with $\mathrm{Na}$ content. A GaN platelet crystal grown at $800^{\circ} \mathrm{C}$ for $72 \mathrm{~h}$ exhibited a mirror-like surface on one side that corresponded to the N-plane, whereas on the other side was the Ga-plane with bumpy features and many steps. The platelet crystal was grown in brown transparent colour.

A schematic diagram to describe the proposed reaction process between the $\mathrm{Na}-\mathrm{Ga}$ melts and $\mathrm{N}_{2}$ in the stainless steel tube container with details of the reaction mechanism is provided in the report. ${ }^{26}$ From the diagram, it is interesting to note that the growth rate along the perpendicular direction to the $c$-axis seemed to be faster than other direction, causing pyramidal and prismatic crystals to grow beneath the melt surface. Increase in the Na content of the initial melt led to a shorter period of the first stage and therefore, the area of the platelet crystal growth spreaded upward. Due to good wettability of Na-Ga melt on the stainless steel, the interface was convex downward and therefore, the crystal growth area spread towards the container wall. This indicates that the stainless-steel container is not a better option for the bulk GaN single crystal growth. For this reason, they have proposed boron nitride (BN) crucible as an alternative container for the stainlesssteel crucible since it has low wettability of Na-Ga melt that could favour the melt to stay at the bottom of the crucible.

Aoki et al. demonstrated a synthesis of bulk GaN single crystal by heating the Ga-Na melt in a BN crucible at $750^{\circ} \mathrm{C}$ for $200 \mathrm{~h}$ with a constant $\mathrm{N}_{2}$ pressure of $5 \mathrm{MPa}^{27}$ This work was an attempt to obtain a bulk GaN single crystal with a larger size and better quality than prior reports. From the experiment, a hexagonal colourless transparent bulk GaN single crystal with a minimum size of $3 \mathrm{~mm}$ in the longest direction was obtained at $r_{\mathrm{Na}}=0.60$. The FWHM from XRD rocking curve scan of the sample was found to be 25 arcsecs, while its carrier concentration was $1-2 \times 10^{18} \mathrm{~cm}^{-3}$ and its mobility was $100 \mathrm{~cm}^{2} \mathrm{~V}^{-1} \mathrm{~s}^{-1}$. Even though the carrier concentration of the sample was 2 order of magnitude smaller than the one previously reported using the sealed stainless steel tube container, it showed excellent optical properties from CL spectrum. No emission peaks or bands related 
to defects or impurities were observable, except for the GaN near-band emissions (NBE) peak at $365 \mathrm{~nm} .{ }^{23}$ Furthermore, the intensity of the NBE emission peak was about 1.7 times higher than the reported one. ${ }^{23}$

In a later report, the Yamane group grew a bulk GaN single crystal using $\mathrm{Na}$ vapour at a temperature of $780^{\circ} \mathrm{C}$ under $\mathrm{N}_{2}$ pressure of $5 \mathrm{MPa}$ for $400 \mathrm{~h}$ in a special apparatus design, as shown in Figure 3. ${ }^{28}$

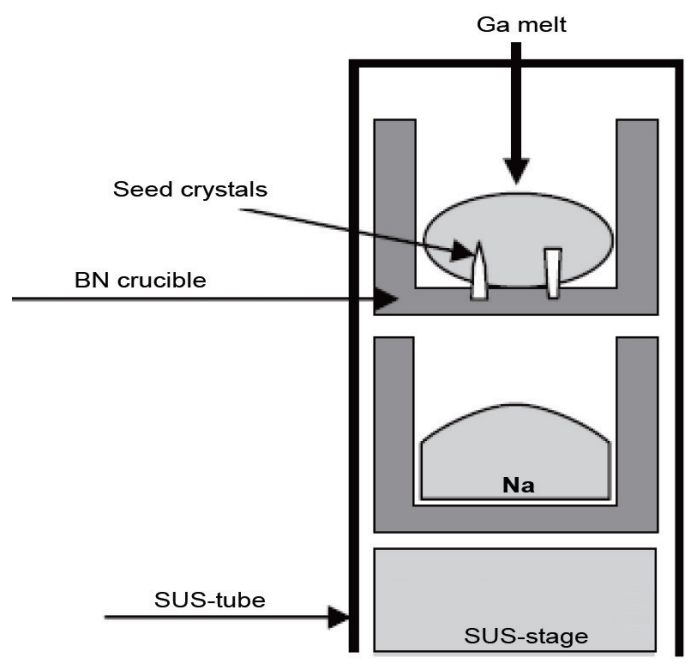

Figure 3: Schematic diagram of apparatus for growing a GaN single crystal on seed crystals using Na vapour supplied from a stainless-steel at the bottom. ${ }^{28}$

The apparatus consists of $\mathrm{BN}$ crucible at the upper part, where the seed crystals were placed together with the Ga melt heated at $\sim 50^{\circ} \mathrm{C}$. There were two holes being introduced inside the bottom wall of the $\mathrm{BN}$ crucible and plugged part of the seed crystals into the holes. The Na source was supplied into the lower crucible to provide the $\mathrm{Na}$ vapour. In previous study, they found that a $\mathrm{Ga}$ melt heated in $\mathrm{Na}$ vapour at $720^{\circ} \mathrm{C}-800^{\circ} \mathrm{C}$ with $\mathrm{N}_{2}$ pressure of $5 \mathrm{MPa}$ absorbed the $\mathrm{Na}$ from the vapour and created a $\mathrm{Na}-\mathrm{Ga}$ melt. A colourless transparent $\mathrm{GaN}$ single crystal was obtained but the crystal was grown on and near the crucible wall. Therefore, the proposed apparatus design was an attempt to minimise this problem. The result from the experiment however showed small grains of skeletal crystals grew on the seed crystals, while colourless prismatic crystals were grown on the crucible wall. They attributed this issue to the depletion of the supply of the Na vapour during the heating. Therefore, its supply over the melt could not be controlled independently using the proposed design. Figure 4(a) shows the seed crystal with $-c$ (N-polar) direction and Figure 4(b), the seed crystal with $+c$ (Ga-polar) direction. The GaN 
crystals were grown on both seed crystals at $780^{\circ} \mathrm{C}$ with $\mathrm{N}_{2}$ pressure of $5 \mathrm{MPa}$ for $400 \mathrm{~h}$. Figures 4(c and e) show the optical micrographs and SEM images, respectively for the grown $\mathrm{GaN}$ crystals on the N-polar seed crystal. On the other hand, Figure 4(d and f) are those of the grown GaN crystals on the Ga-polar seed crystal. The GaN grown crystals exhibit the pyramidal planes of (101) with an angle of $28^{\circ}$ towards the direction of the $c$-axis. The width of the crystals however reduced towards the crucible wall. This is due to the gradient of concentration or temperature.
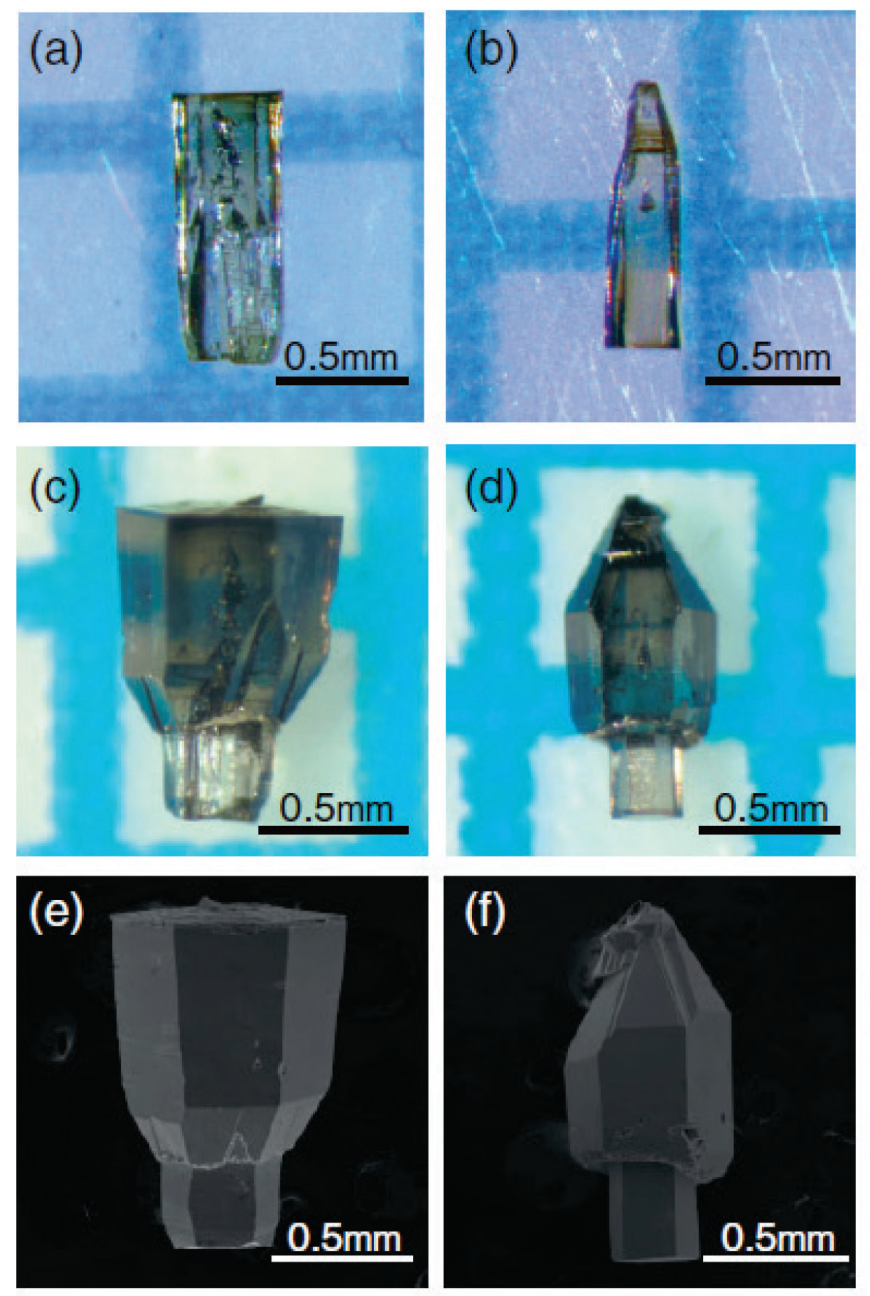

Figure 4: Optical micrographs of the seed crystal with (a) N-polar and (b) Ga-polar, directions, (c and d) optical micrographs, and (e and f) SEM of corresponding $\mathrm{GaN}$ crystals grown on the seed crystal with different direction. ${ }^{28}$ 
Kawamura et al. proposed that the yield of $\mathrm{GaN}$ growth and transparency of the $\mathrm{GaN}$ single crystal can be increased by introducing calcium $(\mathrm{Ca})$ in $\mathrm{Na}$ flux, hence creating Na-Ca system. ${ }^{29}$ The nitrogen dissolution was enhanced by increasing the $\mathrm{Ca}$ ratio up to $5 \mathrm{~mol} \%$, which then led to the increase of yield of GaN growth and the GaN crystal transparency. Figure 5(a) indicates the relationship between the $\mathrm{Ca}$ flux composition and the yield of the GaN crystals, where the experiment was carried-out at $800^{\circ} \mathrm{C}$ for $96 \mathrm{~h}$. On the other hand, Figure 5(b) shows the grown GaN single crystal with $\mathrm{Ca}$ mol\% that has a good transparency. Details analysis from Figure 5(a) found that the yield was increasing with Ca ratio up to $5 \mathrm{~mol} \%$ and reached at the maximum of $13.9 \mathrm{~mol} \%$. Further increase in the Ca ratio did not enhance the GaN synthesis, thereby reducing the yield. In a separate publication, they pointed out that the $\mathrm{Na}-\mathrm{Ca}$ flux resulted in a low dislocation density of $\sim 2 \times 10^{5} \mathrm{~cm}^{-2}$ in a bulk GaN crystal. ${ }^{30}$ This elucidates that only a small ratio of $\mathrm{Ca}$ is required to increase the $\mathrm{GaN}$ yield effectively. In relation to that, the $\mathrm{Na}-\mathrm{Ca}$ flux should be carefully controlled, but this is relatively difficult to do in practice.

(a)

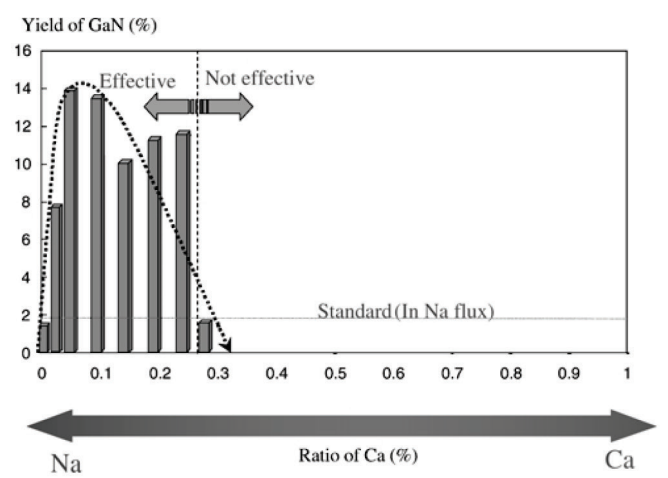

(b)

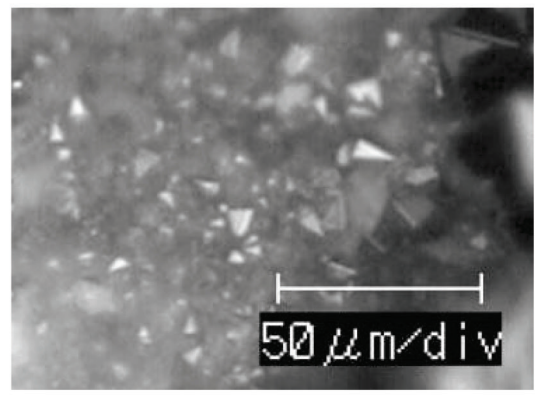

Figure 5: Illustration (a) shows yield of GaN crystal grown with various Ca ratio in Na$\mathrm{Ca}$ flux. Note that the yield is indicated as ratio of GaN crystal grown in flux against metallic Ga of starting material. Illustration (b) shows transparent GaN single crystals grown near the gas-liquid interface in Ca 5 mol\% mixed flux. ${ }^{29}$

The same group continued to fine-tune the growth of bulk GaN crystal by introducing carbon additive into the solution in order to prevent the unfavourable formation of polycrystals $\mathrm{GaN}$ (or parasitic $\mathrm{GaN}$ ) without compromising the yield of GaN. ${ }^{31}$ Such formation is always observed in Na-flux method and it reduces the growth rate of the bulk GaN crystal. It should be worth noting that the carbon did not incorporate into the GaN lattice structure. From the experiment, the effect of the carbon resulted in the increase of growth rate of LPE above $20 \mu \mathrm{m} \mathrm{h}^{-1}$. At the same time, the carbon additive considerably suppressed the formation of the 
polycrystals. A $3 \mathrm{~mm}$ thick GaN in 2" size was obtained. The process of growing a bulk GaN using the LPE approach with the formation of the unwanted polycrystals $\mathrm{GaN}$ is given in the report. They also discussed a comparison study of the amount of polycrystals formed with the GaN crystal, without and with the carbon additive. A photograph of the $3 \mathrm{~mm}$-thick GaN grown with $0.5 \mathrm{at} \%$ of carbon in a large chamber was also presented. At a pressure of $50 \mathrm{~atm}$, more concentrations of carbon were needed to completely eliminate the formation of the polycrystals at $750^{\circ} \mathrm{C}$ as compared to their formation at $800^{\circ} \mathrm{C}$. This is because higher supersaturation occurred at $750^{\circ} \mathrm{C}$. However, there is a possibility that the carbon could be incorporated into the lattice structure of the GaN crystal when its concentration is too high. In this regard, the authors should provide more data of the dependence of the formation of the polycrystals on variation of carbon concentration. This will give a good guideline to other researchers to determine the optimum carbon concentration required to eliminate the entire polycrystals without promoting its incorporation into the grown $\mathrm{GaN}$ crystal. Furthermore, the effectiveness of carbon at different concentration to eliminate the polycrystals may depend on the temperature. However, this subject has been overlooked by many researchers thus far. It would be advantageous to have this "figure of merit" in order to justify the role of carbon additive in GaN crystal growth through Na-flux method.

As a continuity of the work, the group has developed a GaN single crystal with $8.6 \mathrm{~mm}$ long and $5 \mathrm{~mm}$ high. The crystal was grown for $96 \mathrm{~h}$ without the formation of polycrystals using carbon additive through spontaneous nucleation approach, shown in Figure 6(a). ${ }^{32}$ The suppression of the formation of the polycrystals by the carbon additive would fasten the growth of the GaN single crystal. In the experiment, they employed the reported GaN single crystal as the seed crystal. ${ }^{31}$ They found that the growth rate and the growth behaviour changed as the Ga flux increased. Figure 6(b) shows the growth rate and the XRD-FWHM of GaN peak as a function of Ga flux. Obviously, the growth rate is higher at low Ga flux, while the quality of the GaN crystal (as defined by the FWHM of the XRD peak) seemed independent to the flux. They also found that increase in the Ga flux changed the grown GaN crystal from prismatic to pyramidal shape. Despite that, the yield GaN crystals were black. This contradicts to the LPE approach as demonstrated in their previous work. ${ }^{31}$ In the LPE approach, the blackening is always expected at the initial stage of growth and turns into transparent as the growth progresses. Therefore, the solubility of nitrogen for this particular experiment should be increased to minimise the N-deficiency so that a colourless transparent GaN crystal can be obtained. 
(a)

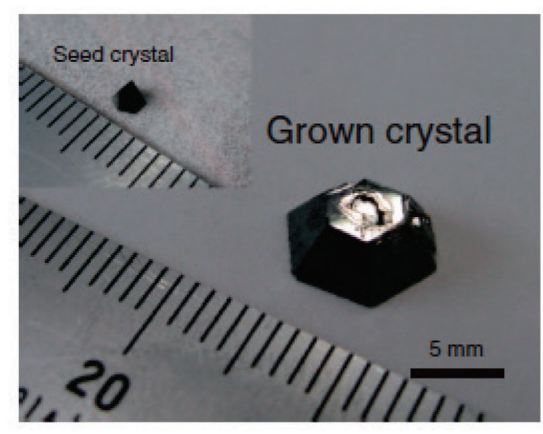

(b)

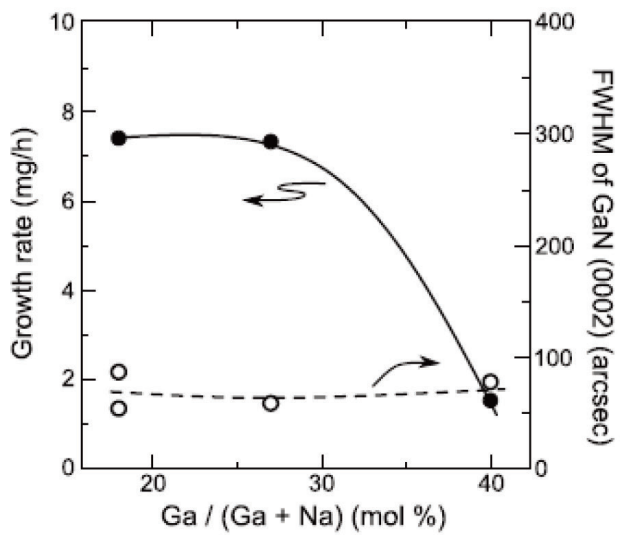

Figure 6: Illustrations of (a) photograph of a blackening bulk GaN crystal with the seed crystal (inset figure), and (b) growth rate and XRD rocking curve FWHM versus Ga flux. ${ }^{32}$

Despite the achievement, the difficulty of producing a large-area bulk GaN single crystal with high quality remains a challenge. In 2012, a major breakthrough in Na-flux method has been made by a group from Osaka University. ${ }^{18}$ Borrowing the concept of necking technique that is the key in Czochralski growth of $\mathrm{Si}$, a prims/prismatic shape and well-faceted bulk GaN crystal with a size of $0.85 \mathrm{~cm}$ in width and $1 \mathrm{~cm}$ in length was successfully grown. The bulk crystal grown for $400 \mathrm{~h}$ exhibited a narrow FWHM peak in parallel and perpendicular directions at 42.8 arcsec and 32.5 arcsec, respectively. Figure 7(a) illustrates details of the growth mechanism of the bulk GaN crystal through the necking technique. Meanwhile, Figure 7(b) indicates the images of the GaN crystal grown at 200, 400 and $600 \mathrm{~h}$. As presented in Figure 7(c), the crystal mass and the aspect ratio increase significantly with growth period. This is due to the increase of the $\mathrm{Sr}$ (strontium) concentration, which is used as the starting materials alongside $\mathrm{Ga}$, $\mathrm{Na}$ and graphite grains in the work. The addition of $\mathrm{Sr}$ into the solution helps the crystal to grow in a prism-shape crystal. It should be noted that the $\mathrm{GaN}$ crystal is not fully transparent and this implies that the group are struggling to overcome the problem related to $\mathrm{N}$-deficiency. 

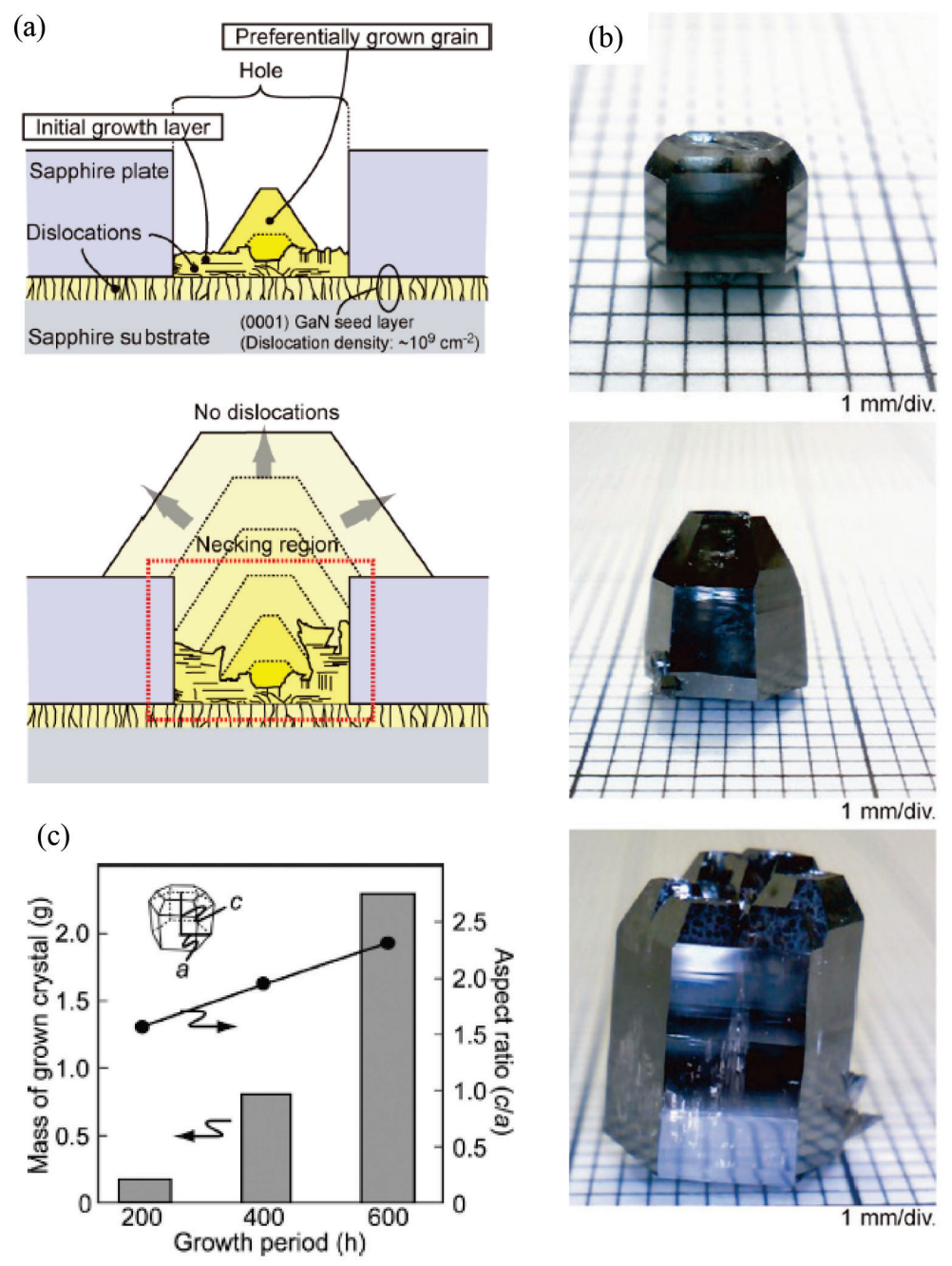

Figure 7: Illustrations of (a) growth mechanism of the bulk GaN single crystal through the necking technique, (b) photograph images of the GaN crystal grown at 200, 400 and $600 \mathrm{~h}$, and (c) crystal mass and aspect ratio as functions of growth period of the bulk GaN crystal. ${ }^{18}$

The Osaka group continued to improve the GaN single crystal growth by proposing point-seed technique. ${ }^{16}$ The solution was stirred and allowed the bulk GaN to grow on the seed crystal. The solution stirring in Na-flux method was demonstrated in previous work by Kawamura et al., whereby the growth rate, flatness and uniformity of LPE-GaN were obtained. ${ }^{20}$ They also added carbon to suppress the formation of the polycrystals on the crucible wall. The experimental setup is shown in Figure 
8(a). Figure 8(b) shows the optical photograph of the $c$-face GaN wafer that was sliced from the bulk GaN crystals after being subjected to chemical-mechanical polish. The yield GaN crystal had a well-faceted structure with size up to $2.1 \mathrm{~cm}$ in a diameter and $1.2 \mathrm{~cm}$ in a height without the presence of the polycrystals. From Figure 8(b), the wafer looks black and this is similar to what they had observed in previous works. Nonetheless, images from Panchormatic CL measurement showed lack of dark spots in the sliced GaN wafer, whereas (006) XRD rocking curve measurement of the wafer revealed that the FWHM was 2.1 arcsec. From these observations, they inferred that the crystal structure of the wafer is almost perfect. Nonetheless, the N-deficiency is still an issue.

(a)
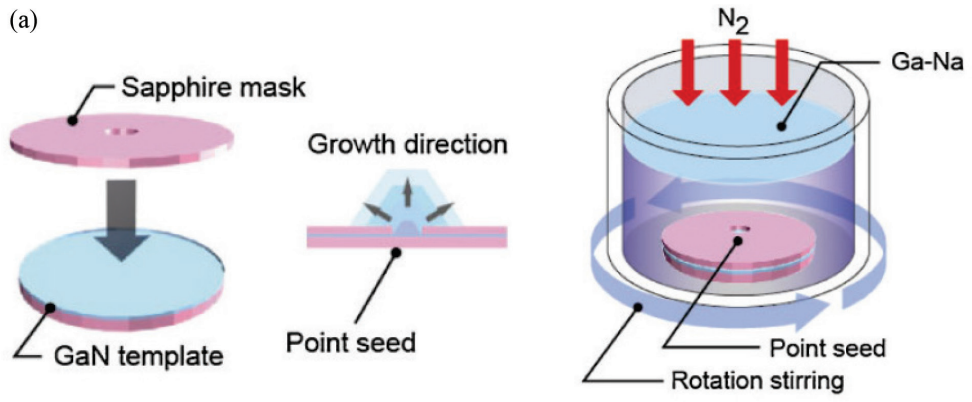

(b)

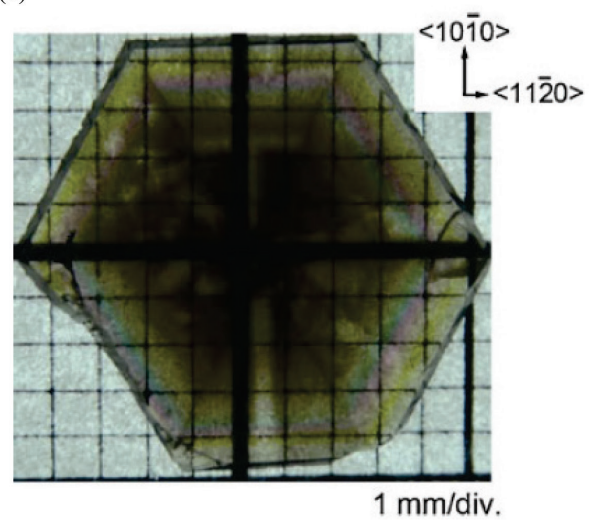

Figure 8: Illustration (a) shows point-seed technique for growing a bulk $\mathrm{GaN}$ single crystal, where the $\mathrm{GaN}$ point seed was produced by mounting a sapphire plate with a small hole of about $0.5-1.5 \mathrm{~mm}$ in diameter on a MOCVD grown $\mathrm{GaN}$ template. The GaN crystal was grown through the hole in the sapphire wafer. Illustration (b) shows optical photograph of $c$-face sliced GaN wafer from the grown crystal. ${ }^{16}$ 
On top of that, the group extended the work by proposing multi-point-seed (MPS) GaN substrate to promote coalescence growth (see Figure 9). This is an effort to increase the diameter of the GaN crystals up to 2". The point seeds were arranged in hexagonal pattern and the neighbouring point seeds were parallel to $a$-direction. Hence, the coalescence direction was corresponding to the $a$-direction of GaN. Each point seed had a diameter in $250 \mu \mathrm{m}$, while the distance between the centres of neighbouring point seeds was $350 \mu \mathrm{m}$. This particular growth was conducted at $870^{\circ} \mathrm{C}, 3.2 \mathrm{MPa}$ for $144 \mathrm{~h}$.
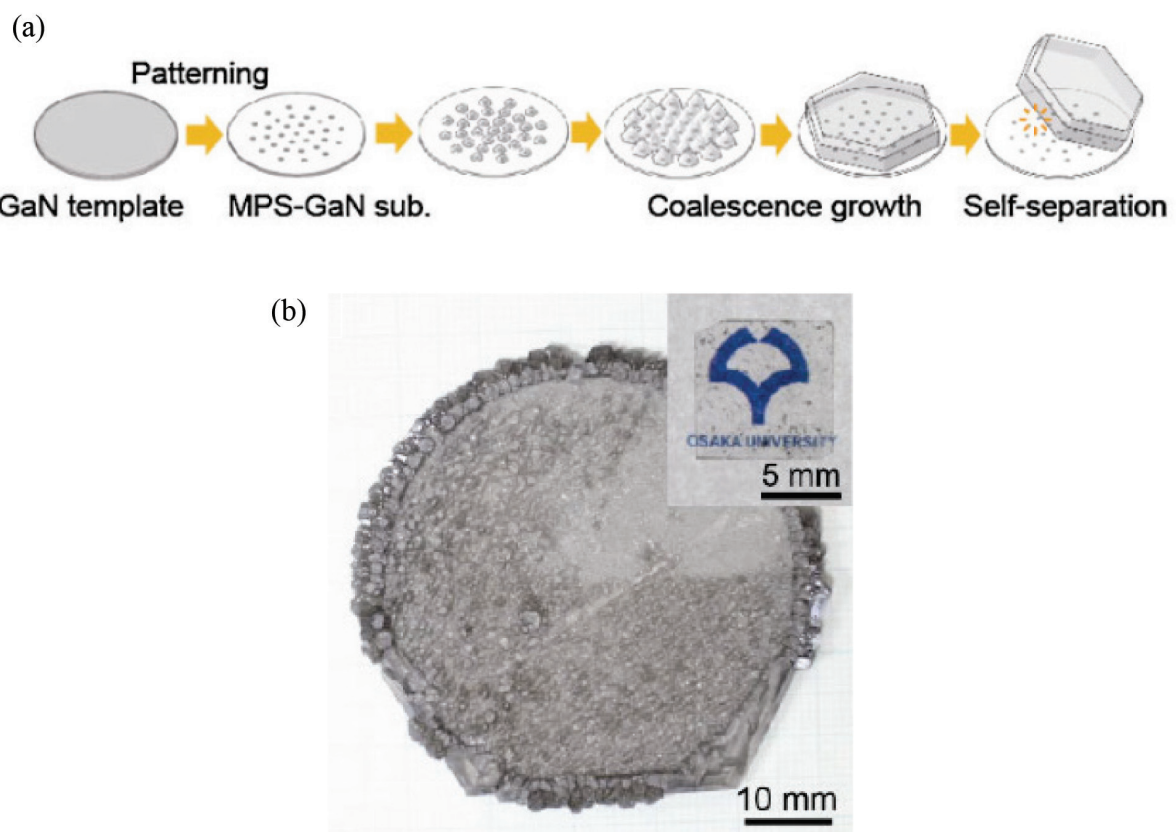

Figure 9: Illustrations of (a) the process of the coalescence growth through multi-pointseed (MPS) technique, and (b) photograph of the grown 2" GaN crystal through the MPS technique. Inset figure is a $10 \times 10 \mathrm{~mm}^{2} c$-face GaN sample sliced from the grown 2 " GaN after the polishing.

A recent work by a group from University of California, Santa Barbara demonstrated a new apparatus design of growing bulk $\mathrm{GaN}$ by implementing a reflux-condensing stem together with usable capsule containing hermetic seal. ${ }^{33}$ Such design could prevent the migration or loss of sodium from the growth environment, as well as allowing better access of $\mathrm{N}_{2}$ to the growing crystal. Furthermore, the reflux-condensing stem has allowed direct monitoring of the melt temperature. They also introduced molybdenum based TZM into the capsule design to enable crucible-free growth of a single GaN crystal from a bulk seed. 
This design could improve the process control and reduce crystal impurity level. In spite of that, the growth rate was lower with respect to other published works. Moreover, the impurity level was higher as confirmed by XRD measurement. The grown GaN crystal was quite black although it had a smooth surface. For future improvement, they suggested to optimise the handling procedures, growth initiation due to poor nucleation, and overall growth conditions. Details of the diagrams of the crucible-free capsule and the bulk GaN crystal grown in the capsule system are given in the report.

The understanding of vacancy-type defects in bulk GaN grown by Na-flux method is important in the process of developing high performance laser diodes and power devices. Uedono et al. reported the defects behaviour using positron annihilation technique. ${ }^{34}$ It was found that pyramidal bulk GaN samples exhibited striation and inhomogeneous colour distributions. Furthermore, decrease in the transparency of the samples implies larger amount of the vacancy-type defects. They identified the defect species as a Ga vacancy coupled with nitrogen vacancies and its origin was coming from the incorporation of oxygen during the growth. Such vacancy however was not detectable for $c$-plane GaN crystal grown on HVPE-GaN or grown by the coalescence growth method. This finding could contribute to a new fundamental solution to overcome the N-deficiency problem in the growth of bulk GaN by Na-flux.

Table 1 summarises the reported bulk GaN crystals as discussed in this review. Statistically, most of the bulk GaN crystals were grown using spontaneous nucleation approach although some views agreed that a large diameter bulk $\mathrm{GaN}$ is more possible with the LPE approach. Meanwhile, the amount of threading dislocations in the samples was found to be lower than $100 \operatorname{arcsec}$ in some experiments. ${ }^{18,27,32}$ Despite of that, the samples are not transparent due to $\mathrm{N}$-deficiency and therefore putting the Na-flux method grown bulk GaN crystals at disadvantage until today. Temperature and pressure were applied at moderate level in most of the experiments. As the Na-flux growth technology keeps progressive, the growth rate of the bulk GaN is becoming higher. However, the growth rate is still lower as compared to HVPE that can grow at $\sim 100 \mu \mathrm{m} \mathrm{h}^{-1}$ with a diameter up to 2". In regards to the issues, more efforts in need to advance the Na-flux method in bulk GaN crystals production. 
Table 1: Details of properties of bulk GaN crystals grown by Na-flux method as reported in selected publications.

\begin{tabular}{|c|c|c|c|c|c|c|c|}
\hline Approach & $\begin{array}{c}\text { XRD } \\
\text { FWHM } \\
(\operatorname{arcsec})\end{array}$ & $\begin{array}{l}\text { Size }(\mathrm{mm}) / \\
\text { area }\left(\mathrm{mm}^{2}\right)\end{array}$ & $\begin{array}{c}\text { Temperature } \\
\left({ }^{\circ} \mathrm{C}\right)\end{array}$ & $\begin{array}{l}\text { Time } \\
\text { (hour) }\end{array}$ & $\begin{array}{c}\text { Pressure } \\
(\mathrm{MPa})\end{array}$ & $\begin{array}{l}\text { Type of } \\
\text { structure }\end{array}$ & $\begin{array}{c}\text { Fully } \\
\text { transparent/ } \\
\text { colourless } \\
(\text { Yes } / \mathrm{No})\end{array}$ \\
\hline $\begin{array}{l}\text { SN } \\
\operatorname{Ref}^{17}\end{array}$ & - & $\begin{array}{l}0.5-1.0 \\
1.0-2.0\end{array}$ & $600-800$ & $24-96$ & - & $\begin{array}{c}\text { Pyramidal } \\
\text { platelet }\end{array}$ & No \\
\hline $\begin{array}{l}\text { SN } \\
\operatorname{Ref}^{23}\end{array}$ & - & $\begin{array}{c}0.4-0.7 \\
0.5 \times 1.0\end{array}$ & 750 & 100 & - & $\begin{array}{l}\text { Prismatic- } \\
\text { platelet- } \\
\text { granular }\end{array}$ & Yes \\
\hline $\begin{array}{l}\text { SN } \\
\operatorname{Ref}^{25}\end{array}$ & - & $\begin{array}{c}0.005- \\
0.300\end{array}$ & $700-850$ & 200 & $1-5$ & $\begin{array}{l}\text { Platelet } \\
\text { prismatic }\end{array}$ & Yes \\
\hline $\begin{array}{l}\text { SN } \\
\operatorname{Ref}^{26}\end{array}$ & - & $\begin{array}{c}0.7 \\
1.0-2.0 \\
\text { Thickness: } \\
0.05\end{array}$ & $650-840$ & $6-300$ & $<15$ & $\begin{array}{l}\text { Platelet } \\
\text { prismatic }\end{array}$ & No \\
\hline $\begin{array}{l}\text { SN } \\
\operatorname{Ref}^{27}\end{array}$ & 25 & 3 & 750 & 200 & 5 & Platelet & Yes \\
\hline $\begin{array}{l}\text { SN } \\
\operatorname{Ref}^{28}\end{array}$ & 360 & $\begin{array}{c}\text { Thickness: } \\
0.15\end{array}$ & 780 & 400 & 5 & Prismatic & - \\
\hline $\begin{array}{l}\text { LPE } \\
\text { Ref }^{29}\end{array}$ & - & - & 800 & 96 & - & - & Yes \\
\hline $\begin{array}{l}\text { LPE } \\
\operatorname{Ref}^{31}\end{array}$ & - & $\begin{array}{c}50.8(2 ”) \\
\text { Thickness: } \\
3.0\end{array}$ & $750-800$ & 150 & - & - & - \\
\hline $\begin{array}{l}\mathrm{SN} \\
\operatorname{Ref}^{32}\end{array}$ & 70 & $\begin{array}{l}8.6 \text { (long) } \\
5.0 \text { (high) }\end{array}$ & 860 & 96 & 3.5 & $\begin{array}{l}\text { Prismatic- } \\
\text { pyramidal }\end{array}$ & No \\
\hline $\begin{array}{l}\text { SN } \\
\operatorname{Ref}^{18}\end{array}$ & 42.8 & $\begin{array}{c}8.5 \text { (width) } \\
10.0 \\
\text { (length) }\end{array}$ & 890 & 600 & 4 & Prismatic & No \\
\hline $\begin{array}{l}\text { SN } \\
\text { Ref }^{16}\end{array}$ & $\begin{array}{c}2.1 \\
\text { in }(006) \\
\text { scan }\end{array}$ & $\begin{array}{c}21 \\
\text { (diameter) } \\
12 \text { (height) }\end{array}$ & 870 & 400 & 3.4 & - & No \\
\hline $\begin{array}{l}\mathrm{LPE} \\
\operatorname{Ref}^{33}\end{array}$ & 731 & $10 \times 10$ & 861 & 103 & 4.7 & Square & No \\
\hline
\end{tabular}

${ }^{a} S N$ : Spontaneous nucleation

${ }^{b}$ LPE: Liquid phase epitaxy 


\section{CONCLUSION}

Development of bulk GaN crystals by Na-flux method, as reported across literature was briefly reviewed here. Huge efforts have been made to improve the yield of bulk GaN crystals, while increasing their growth rate for up scaling to mass production. From the review, N-deficiency is a long-standing "stumbling block" to grow highly transparent bulk $\mathrm{GaN}$ although some approaches have been proposed to overcome the problem (e.g., increasing the $\mathrm{N}$ solubility). It is suggested that more in-depth investigation works carried out to identify the fundamental causes to this problem. Another key issue is the growth time for larger size, area and thickness of the bulk GaN crystals by Na-flux method remains longer than HVPE growth. One possible way is to grow them in a larger chamber, while fine-tuning the Ga flux and carbon additive. The use of BN crucible seems not important in the effort to improve the growth. With further improvement, the proposed cruciblefree design by the University of California, Santa Barbara group has a bigger potential to advance the bulk GaN growth at low cost production. Looking at a local perspective, the technology of growing bulk GaN by Na-flux method is not well established in Malaysia so far. With increasing demands in semiconductor industry, the market value for bulk GaN is expected to reach over USD 4 billion by $2020 .{ }^{35}$ Hence, it is timely to consider to initiate this technology in Malaysia. This particular field of research has a huge prospect to propel the electric and electronic (E\&E) sector in this country.

\section{ACKNOWLEDGEMENTS}

This work was conducted under Bridging Fund (304/CINOR/6316170) and Research University-Individual (account number: 1001/CINOR/811302), both from Universiti Sains Malaysia, Malaysia.

\section{REFERENCES}

1. Park, J. et al. (2016). Dependence of adhesion strength between GaN LEDs and sapphire substrate on power density of UV laser irradiation. Appl. Surf. Sci., 384, 353-359, https://doi.org/10.1016/j.apsusc.2016.05.078.

2. Compound Semiconductor. (2016). Sapphire substrate continues to dominate LED market. LED Journal, 19 April. Retrieved 10 January 2017 from http://www. ledjournal.com/main/news/sapphire-substrate-continues-to-dominate-led-market/.

3. Tanikawa, T. et al. (2018). Three-dimensional imaging of threading dislocations in GaN crystals using two-photon excitation photoluminescence. Appl. Phys. Expr., 11, 031004-1-031004-4, https://doi.org/10.7567/APEX.11.031004. 
4. Kim, J. et al. (2014). Influence of V-pits on the efficiency droop in InGaN/GaN quantum wells. Opt Expr., 22, A857-A866, https://doi.org/10.1364/OE.22.00A857.

5. Jie-Jun, W. et al. (2015). GaN substrate and GaN homo-epitaxy for LEDs: Progress and challenges. Chin. Phys. B, 24, 068106-1-068106-10.

6. Weyers, M. et al. (2008). GaN substrates by HVPE. Proc. SPIE, 6910, 691001, https://doi.org/10.1117/12.764405.

7. Fujito, K. et al. (2009). Bulk GaN crystals grown by HVPE. J. Cryst. Growth, 310, 3011-3014, https://doi.org/10.1016/j.jcrysgro.2009.01.046.

8. Grzegory, I. et al. (2006). Growth of bulk GaN by HVPE on pressure grown seeds. Proc. SPIE., 6121, 612107, https://doi.org/10.1117/12.645976.

9. Lee, H. Y. et al. (2014). The control of mechanical bow for GaN substrate grown by HVPE with relatively longer radius of lattice curvature. Phys. Stat. Sol. C, 11, 477-482, https://doi.org/10.1002/pssc.201300514.

10. Foronda, H. M. et al. (2016). Curvature and bow of bulk GaN substrates. J. Appl. Phys., 120, 035104-1-035104-7, https://doi.org/10.1063/1.4959073.

11. Boćkowski, M. et al. (2011). High nitrogen pressure solution growth of bulk GaN in "feed-seed" configuration. Phys. Stat. Sol. A, 208, 1507-1510, https://doi. org/10.1002/pssa.201000981.

12. Pimputkar, S. et al. (2014). Improved growth rates and purity of basic ammonothermal GaN. J. Cryst. Growth, 403, 7-17, https://doi.org/10.1016/j. jcrysgro.2014.06.017.

13. Hashimoto, T. et al. (2014). Ammonothermal bulk GaN growth and its processing. Sens. Mater., 26, 385-392.

14. Masuda, Y. et al. (2016). Convection patterns and temperature fields of ammonothermal GaN bulk crystal growth process. Jpn. J. Appl. Phys., 55, 05FC031-05FC03-3, http://doi.org/10.7567/JJAP.55.05FC03.

15. Kawamura, F et al. (2009). Growth of GaN single crystals with extremely low dislocation density by two-step dislocation reduction. J. Cryst. Growth, 311, 30193024, https://doi.org/10.1016/j.jcrysgro.2009.01.125.

16. Imade, M. et al. (2014). Growth of bulk GaN crystals by the Na-flux point seed technique. Jpn. J. Appl. Phys., 53, 05FA06-1-05FA06-5.

17. Yamane, H. et al. (1997). Preparation of GaN single crystals using a Na flux. Chem. Mater., 9(2), 413-416, https://doi.org/10.1021/cm960494s.

18. Imade, M. et al. (2012). Centimeter-sized bulk GaN single crystals grown by the Na-flux method with a necking technique. Cryst. Growth Des., 12, 3799-3805, https://doi.org/10.1021/cg300643r.

19. Zhou, M. et al. (2014). Growth of GaN crystals by the Na flux method under a temperature gradient. J. Electron. Mater., 43, 1219-1225, https://doi.org/10.1007/ s11664-014-2996-6.

20. Kawamura, F. et al. (2006). Growth of a two-inch GaN single crystal substrate using the Na flux method. Jpn. J. Appl. Phys., 45, L1136-L1138, https://doi.org/ 10.1143/JJAP.45. L1136.

21. Mori, Y. et al. (2012). Growth of bulk GaN crystal by Na flux method under various conditions. J. Cryst. Growth, 350, 72-74, https://doi.org/10.1016/j. jcrysgro.2011.12.026. 
22. Mori, Y. et al. (2011). Growth of bulk GaN crystals by Na flux method. Phys. Status Sol. C, 8, 1445-1449, https://doi.org/10.1002/pssc.201000911.

23. Yamane, H. et al. (1998). Morphology and characterization of GaN single crystals grown in a Na flux. J. Cryst. Growth, 186, 8-12, https://doi.org/10.1016/S00220248(97)00480-6.

24. Hageman, P. R. et al. (2004). N-type doping of wurtzite GaN with germanium grown with plasma-assisted molecular beam epitaxy. J. Cryst. Growth, 267, 123128, https://doi.org/10.1016/j.jcrysgro.2004.03.024.

25. Aoki, M. et al. (2001). Growth conditions and morphology of GaN single crystals fabricated by the Na flux method. J. Ceram. Soc. Jpn., 109, 858-862, https://doi. org/10.2109/jcersj.109.1274_858.

26. Yamane, H. et al. (2000). GaN single crystal growth from a Na-Ga melt. J. Mater. Sci., 35, 801-808.

27. Aoki, M. et al. (2000). Growth of GaN single crystals from a Na-Ga melt at $750^{\circ} \mathrm{C}$ and $5 \mathrm{MPa}$ of $\mathrm{N}_{2}$. J. Cryst. Growth., 218, 7-12, https://doi.org/10.1016/S00220248(00)00518-2.

28. Yamada, T. \& Yamane, H., (2006). Seeded growth of GaN single crystals by Na flux method using Na vapor. Jpn. J. Appl. Phys., 45, L898-L900.

29. Kawamura, F. et al. (2002). Synthesis of bulk GaN single crystals using Na-Ca flux. Jpn. J. Appl. Phys., 41, L1440-11442.

30. Kawamura, F. et al. (2003). Growth of transparent, large size GaN single crystal with low dislocations using Ca-Na flux system. Jpn. J. Appl. Phys., 42, L729L731.

31. Kawamura, F. et al. (2008). Effect of carbon additive on increases in the growth rate of 2 in GaN single crystals in the Na flux method. J. Cryst. Growth, 310, 3946-3949, https://doi.org/10.1016/j.jcrysgro.2008.06.008.

32. Imade, M. et al. (2010). Growth of large GaN single crystals on high-quality GaN seed by carbon-added Na flux method. Appl. Phys. Expr., 3, 075501-1-075501-3, https://doi.org/10.1143/APEX.3.075501.

33. Von Dollen, P. et al. (2016). A new system for sodium flux growth of bulk GaN. Part I: System development. J. Cryst. Growth., 456, 58-66, https://doi.org/10.1016/j. jcrysgro.2016.07.044.

34. Uedono, A. et al. (2017). Vacancy-type defects in bulk GaN grown by the Naflux method probed using positron annihilation. J. Cryst. Growth., 475, 261-265, https://doi.org/10.1016/j.jcrysgro.2017.06.027.

35. Semiconductor Today. (2015). Demand for larger diameters to boost GaN substrate market from \$2.2bn in 2014 to \$4bn by 2020. Retrieved 15 February 2017 from http://www.semiconductor-today.com/news_items/2015/sep/industryarc_030915. shtml. 